\title{
Influence of previous exposure to human parvovirus B19 infection in explaining susceptibility to rheumatoid arthritis: an analysis of disease discordant twin pairs
}

\author{
A H Hajeer, A J MacGregor, A S Rigby, W E R Ollier, D Carthy, A J Silman
}

\begin{abstract}
Objectives-To assess the association between exposure to parvovirus B19 and susceptibility to rheumatoid arthritis (RA).

Methods-One hundred and fifty five twin pairs (76 monozygotic (MZ) and 79 dizygotic (DZ)), discordant for RA, were tested for the presence of IgG antiparvovirus antibodies using ELISA. The data obtained were analysed using conditional logistic regression, from which odds ratios and $95 \%$ confidence intervals were calculated.

Results-Overall, there was no association between exposure to parvovirus and RA $(O R=1 \cdot 2,95 \%$ CI: 0·7-1·7). However, in two subgroups there was a suggestion of an association. These were: (1) pairs where the affected twin was rheumatoid factor (RF) seronegative $(O R=2 \cdot 0,95 \%$ CI: $0 \cdot 9-12 \cdot 4)$ and (2) in opposite-sexed twin pairs where the affected twin was female (OR = 3.0, 95\% CI: 0.9-11·6).

Conclusion-Previous exposure to parvovirus infection did not explain disease susceptibility in both $\mathrm{MZ}$ and $\mathrm{DZ}$ discordant pairs with rheumatoid arthritis. This infection, however, might be relevant in some subgroups.
\end{abstract}

(Ann Rheum Dis 1994; 53: 137-139)

An infectious trigger for rheumatoid arthritis is appealing as an explanation for the environmental component in the disease's PCR, in $75 \%$ of synovial biopsies of patients discordant (76) monozygotic and a similar number of disease discordant dizygotic twin pairs were included in our study.

\section{Patients and methods}

The subjects recruited in this study were part of the ARC National RA twin study, which is described in detail elsewhere. ${ }^{9}$ All the affected twins satisfied the modified 1987 ARA criteria for RA. ${ }^{10}$ All individuals were also tested for current rheumatoid factor using the latex test. A titre of 1 in 40 or greater was considered positive.

IgG anti-HPV was assayed using an ELISA kit (Progen, Heidelberg). Serum samples were diluted 1:100 and the rest of the procedure was carried out according to the protocol supplied. The cut-off value of the test was calculated according to the manufacturer's instructions and the results were scored $0-3$ (zero being negative, 1 weak, 2 positive and 3 highly positive). We combined the 0 and 1 scores as negative and the 2 and 3 scores as positive for analysis. The HLA-DR status of all study individuals haḍ been ascertained using standard techniques.

A matched paired analysis was carried out. This analysis ignores the pairs that are identical in their exposure (either both HPV positive or both HPV negative) and compares the ratio of the exposure discordant pairs, that is, RA twin positive/unaffected twin negative: RA twin negative/unaffected twin positive. This ratio is equivalent to the odds ratio, and the precision of the estimate was assessed by the $95 \%$ confidence interval.

\section{Results}

There were some differences in the clinical features of RA beween individuals with RA who were HPV positive when compared with those who were HPV negative (table 1). The HPV positive group had a higher proportion that were female, was less likely to be seropositive for rheumatoid factor and less likely to have erosive and nodular disease. These differences, however, were minor.

In total, 103 pairs $(66 \%)$ were concordant in their exposure to HPV: $26 \mathrm{MZ}$ and $22 \mathrm{DZ}$ twin pairs were concordant for HPV seropositivity and $29 \mathrm{MZ}$ and $26 \mathrm{DZ}$ twin pairs for HPV seronegativity (table 2 ). The analysis of the aetiology but remains unsupported by seroepidemiological data. Of the candidate infectious agents proposed, human parvovirus B19 (HPV) has attracted interest because of reports in adults of an arthropathy following infection that resembles RA and which may persist. ${ }^{1-6} \mathrm{HPV}$ has also been found to invade joints and viral DNA has been detected in the synovial fluid of a patient with polyarthralgia. ${ }^{7}$ More recently, HPV DNA was detected, using with RA compared with only $16 \cdot 7 \%$ of nonRA, implicating the virus in RA. ${ }^{8}$

In this report we have studied RA discordant twin pairs, using a case-control design, to evaluate the risk associated with previous exposure to HPV and RA. All the disease

ARC Epidemiology
Research Unit,
Manchester University
Medical School,
Manchester, United
Kingdom
A H Hajeer
A J MacGregor
A S Rigby
W E R Ollier
D Carthy
A J Silman
Correspondence to:
Professor Alan J Silman,
ARC Epidemiology Research
Unit,
Stopford Building,
University of Manchester,
Oxford Road,
Manchester M13 9PT,
United Kingdom.
Accepted for publication
3 November 1993


Table 1 Clinical features in human parvovirus positive and negative $R A$-affected individuals

\begin{tabular}{|c|c|c|c|c|c|c|}
\hline & \multicolumn{2}{|c|}{ HPV positive } & \multicolumn{2}{|c|}{ HPV negative } & \multirow[t]{2}{*}{ Difference } & \multirow[t]{2}{*}{$(95 \% C I)$} \\
\hline & No & $\%$ & No & $\%$ & & \\
\hline \multirow[t]{2}{*}{$\begin{array}{l}\text { Female } \\
\text { RF positive } \\
\text { Erosive } \\
\text { Nodular } \\
\text { HLA-DR4 positive }\end{array}$} & $\begin{array}{l}67 / 76 \\
65 / 76 \\
57 / 68 \\
38 / 76 \\
49 / 76\end{array}$ & $\begin{array}{l}88 \cdot 2 \% \\
85 \cdot 5 \% \\
83 \cdot 8 \% \\
50 \cdot 0 \% \\
64 \cdot 5 \%\end{array}$ & $\begin{array}{l}62 / 79 \\
72 / 79 \\
70 / 76 \\
45 / 79 \\
54 / 79\end{array}$ & $\begin{array}{l}78 \cdot 5 \% \\
91 \cdot 1 \% \\
92 \cdot 1 \% \\
57 \cdot 0 \% \\
68 \cdot 4 \%\end{array}$ & $\begin{array}{r}9 \cdot 7 \% \\
-5 \cdot 6 \% \\
-8 \cdot 3 \% \\
-7 \cdot 0 \% \\
-3 \cdot 9 \%\end{array}$ & $\begin{array}{c}(-1 \cdot 9 \%,+21 \cdot 3 \%) \\
(-15 \cdot 7 \%,+4 \cdot 5 \%) \\
(-18 \cdot 9 \%,+2 \cdot 4 \%) \\
(-2 \cdot 3 \%,+8 \cdot 7 \%) \\
(-18 \cdot 7 \%,+11 \cdot 0 \%)\end{array}$ \\
\hline & Mean & $(S D)$ & Mean & $(S D)$ & Difference & $(95 \% C I)$ \\
\hline $\begin{array}{l}\text { Age } \\
\text { Age of disease onset }\end{array}$ & $\begin{array}{l}53 \cdot 4 \\
39 \cdot 3\end{array}$ & $\begin{array}{l}(12 \cdot 2) \\
(12 \cdot 5)\end{array}$ & $\begin{array}{l}53 \cdot 4 \\
38 \cdot 5\end{array}$ & $\begin{array}{l}(11 \cdot 7) \\
(12 \cdot 6)\end{array}$ & $\begin{array}{l}0 \cdot 0 \mathrm{y} \\
0 \cdot 8 \mathrm{y}\end{array}$ & $\begin{array}{l}(-3.8 \mathrm{y},+3.8 \mathrm{y}) \\
(-3.2 \mathrm{y},+4.8 \mathrm{y})\end{array}$ \\
\hline
\end{tabular}

*data on erosions was unavailable in 11 affected individuals.

Table 2 Anti-human parvovirus IgG distribution within twin pairs

\begin{tabular}{|c|c|c|c|}
\hline \multirow[t]{2}{*}{$\mathrm{I}: \mathrm{MZ}$ pairs } & & \multicolumn{2}{|c|}{ Non-affected twin } \\
\hline & & pos & neg \\
\hline \multirow[t]{2}{*}{ Affected twin } & $\begin{array}{l}\text { pos } \\
\text { neg }\end{array}$ & $\begin{array}{l}26 \\
10\end{array}$ & $\begin{array}{l}11 \\
29\end{array}$ \\
\hline & & $\begin{array}{l}\text { Odds Ratio } \\
1 \cdot 1\end{array}$ & $\begin{array}{l}(95 \% \mathrm{CI}) \\
(0 \cdot 4-2 \cdot 9)\end{array}$ \\
\hline \multirow[t]{2}{*}{ II: DZ pairs } & & \multicolumn{2}{|c|}{ Non-affected twin } \\
\hline & & pos & neg \\
\hline \multirow[t]{2}{*}{ Affected twin } & $\begin{array}{l}\text { pos } \\
\text { neg }\end{array}$ & $\begin{array}{l}22 \\
14\end{array}$ & $\begin{array}{l}17 \\
26\end{array}$ \\
\hline & & $\begin{array}{l}\text { Odds Ratio } \\
1 \cdot 2\end{array}$ & $\begin{array}{l}(95 \% \mathrm{CI}) \\
(0 \cdot 6-2 \cdot 7)\end{array}$ \\
\hline \multirow[t]{2}{*}{ III: All pairs } & & \multicolumn{2}{|c|}{ Non-affected twin } \\
\hline & & pos & neg \\
\hline \multirow[t]{2}{*}{ Affected twin } & $\begin{array}{l}\text { pos } \\
\text { neg }\end{array}$ & $\begin{array}{l}48 \\
24\end{array}$ & $\begin{array}{l}28 \\
55\end{array}$ \\
\hline & & $\begin{array}{l}\text { Odds Ratio } \\
1.2\end{array}$ & $\begin{array}{l}(95 \% \mathrm{CI}) \\
(0 \cdot 7-1 \cdot 7)\end{array}$ \\
\hline
\end{tabular}

pairs discordant for exposure showed no association between RA and HPV in either the $\mathrm{MZ}$ or DZ pairs (table 2).

Exposure to HPV was then analysed in various subgroups. There was an increased risk of RA associated with exposure to the virus in the $M Z$ pairs where the affected twin was rheumatoid factor negative $(\mathrm{OR}=2 \cdot 0,95 \% \mathrm{CI}$ $0 \cdot 9-12 \cdot 4)$. There were too few seronegative $\mathrm{DZ}$ pairs for useful analysis. Further, in the opposite-sexed DZ twin pairs there was an association between HPV and RA (OR $=3 \cdot 0$, $95 \%$ CI $0.9-11 \cdot 6$ ). In all these pairs, the females were affected and the males were unaffected. In same-sexed pairs, both $M Z$ and $\mathrm{DZ}$, there was no evidence for an association.

There was no evidence of any difference in the association between exposure to HPV and RA in relation to HLA-DR4 status.

\section{Discussion}

The major finding of this study is that HPV infection does not explain differences in disease susceptibility in disease discordant twins. Our findings are in keeping with those of Deighton et al who failed to find an association between RA HPV exposure in a sample of disease discordant HLA identical same-sexed sibling pairs. ${ }^{11}$

There was some evidence in our data to suggest that there was an increased association with HPV in those twin pairs in which the affected twin had seronegative RA. An association was also found in opposite-sexed, disease discordant, dizygotic twins. This latter association could not be explained by a background of increased seropositivity risk in females in general since, in the group as a whole, no increased rate of seropositivity was observed in non-RA females compared with non-RA males.

The advantage of using disease discordant twins in a case control study is that the control group is perfectly matched for age and genetic factors as well as unknown possible confounders related to socio-economic conditions. A hazard of this approach is the problem of over-matching.

Over-matching has limited the scope of the present twin study in examining the association between exposure to other infectious agents and RA. Many infectious agents potentially implicated in the aetiology of RA, for example measles, mumps or rubella, occur with a high incidence in childhood and early adult life and a high concordance for exposure would be expected in this adult group of twin pairs. Serological evidence of infection by these agents was not sought in the present study.

Serological evidence of infection by Epstein Barr virus was investigated in our study using ELISA; however, all the samples studied showed serology indicative of previous exposure. No association between EBV and RA could therefore be inferred. Human parvovirus exposure, by contrast, occurs less commonly and new cases of exposure occur throughout adult life. $^{12}$ The association between exposure and disease is therefore more likely to be detected in a cross-sectional study. The effect of exposure to HPV was therefore more suitable for study using the twin design and in the present study there was sufficient exposure to discordant pairs (52) to examine the risk associated with exposure.

One difficulty in this analysis is that the presence of IgG anti-HPV antibody indicates previous infection but does not indicate its precise timing. Thus we have no information on the temporal relationship between disease onset and infection. This information would ideally have been obtained by collecting sera in both twin and co-twin at the time of disease onset in the affected twin.

HPV infection produces an arthropathy as part of its clinical picture which may resemble rheumatoid arthritis. ${ }^{5}$ Our data suggesting an association between HPV infection and seronegative rheumatoid arthritis may be explained by the apparent RA individual in the discordant pairs having a parvovirus arthropathy. Inevitably there is some circularity in this argument, particularly as currently available classification criteria for rheumatoid arthritis are insufficiently discriminatory in this respect. Parvovirus arthropathy is classically seronegative and non-erosive and, although most 
of the HPV negative probands were both seropositive and erosive, there was a suggestion that these features were less common in the HPV positive group.

Previous reports have suggested that HLADR4 carried an increased risk for susceptibility to develop arthritis following infection with $\mathrm{HPV}^{12}$ and this is obviously of interest given that it is this allele that it is clearly linked to the development of rheumatoid arthritis. ${ }^{13}$ In our data, however, no such association could be demonstrated.

Rheumatoid arthritis is likely to represent the end result of a large number of aetiological insults. Given this aetiological heterogeneity, it therefore makes it very difficult to demonstrate associations in studies of relatively small numbers of individuals. Subgrouping the disease on clinical, serological or immunogenetic grounds, offers a useful avenue for pursuing such enquiries. In summary, these data provide little support for a widespread effect of human parvovirus infection in explaining susceptibility to rheumatoid arthritis.

We are grateful to Ms Ann Myerscough for technical assistance.
1 Anderson M J, Cohen B J. Human parvovirus B19 infection in the United Kingdom 1984-1986 (letter). Lancet 1987; I: $738-9$.

2 Yamashita K, Matsunaga Y, Taylor-Wiedeman J, Yamazaki S. A significant age shift of the human parvovirus B19 antibody prevalence among adults in Japan observed in a decade. Fpn $\mathcal{F}$ Med Sci Biol 1992; 45: 49-58.

3 Koch W C. Adler S P. Human parvovirus B19 infections in women of childbearing age and within families. Pediatr Infect Dis ₹ 1989; 8: 83-7.

4 Anderson M J, Jones S E, Fisher-Hoch S P, et al. Human parvovirus, the cause of erythema infectiosum (fifth disease)? (letter). Lancet 1983; I: 1378

5 White D G, Woolf A D, Mortimer P P, Cohen B J, Blake D R, Bacon P A. Human parvovirus arthropathy. Lancet 1985; I: 419-21.

6 Reid D M, Reid T M S, Brown T, Rennie J A N. Human parvovirus-associated arthritis: a clinical laboratory description. Lancet 1985; I: 422-25.

7 Dijkmans B A C, van Elsacker-Niele A $M$ W, Salimans $M$ M M, van Albada-Kuipers G A, de Vries E, Weiland $H$ T. Human parvovirus B19 DNA in synovial fluid. Arthritis T. Human parvovirus B19

8 Saal J G, Steidle M, Einsele H, Müller C A, Fritz P, Zacher $\mathrm{J}$. Persistence of $\mathrm{B} 19$ parvovirus in synovial membranes of patients with rheumatoid arthritis. Rheumatol Int 1992; 12: $147-51$.

9 Silman A J, MacGregor A J, Holligan S, et al. Disease concordance in a nationwide study of twins with rehumatoid arthritis. Br ₹Rheumatol 1993; 32: 903-7.

10 MacGregor A J, Ollier W E R, Silman A J. Modification of ARA criteria for theumatoid arthritis for use in population ARA criteria for rheumatoid arthritis for use in p
surveys. Br $\mathcal{f}$ Rheumatol (suppl 2) 1992; 30: 37 .

11 Deighton C M, Madeley, C R, Walker D J. Antiviral antibodies in rheumatoid arthritis discordant HLAidentical same-sexed sibling pairs. Letter. $B r \mathcal{F}$ Rheumatol 1992; 31(5): 357-8.

12 Klouda P T, Corbin S A, Bradley B A, Cohen B J, Woolf A D. HLA and acute arthritis following human parvovirus infection. Tissue Antigens 1986; 28: 318-19.

13 Stastny P. Association of the B-cell alloantigen DRw4 with rheumatoid arthritis. $N$ Engl F Med 1978; 298: 869-71. 